\title{
Selection of compositions of ceramic masses based on industrial wastes using mathematical planning methods
}

\author{
Khungianos Yavruyan ${ }^{1, *}$, Evgeniy Gaishun ${ }^{1}$, Vladimir Kotlyar $^{1}$, Irina Serebryanaya ${ }^{1}$, \\ Anastasiya Filippova ${ }^{1}$, and Alexey Gaishun ${ }^{1}$ \\ ${ }^{1}$ Don state technical university, 344002, Ploshad' Gagarina 1, Rostov-on-Don, Rostov Oblast, Russia
}

\begin{abstract}
This paper reviews the issue of selecting the compositions of ceramic masses for the production of ceramic blocks made out of technogenic raw materials of a coal series using the methods of mathematical planning. The possibility of replacing classic clay raw materials with non-traditional coal technogenic raw materials (screenings of heaps), which are formed during the processing of heaps with the aim of extracting coal, is considered. The reasons for the growing interest in this technogenic raw material were the reduction of the base of high-quality clay raw materials, the large number of accumulated heaps, as well as the need to reduce the cost of production of ceramic blocks.
\end{abstract}

\section{Perspective raw materials for the production of ceramic stones.}

In recent years, active development of heaps of East Donbass with the goal of coal extraction has been carried out, which has significantly increased the interest of the construction materials industry in by-products of their development. The concept of using energy-saving and environmentally friendly technologies in the production of ceramic building materials is becoming increasingly important in the world. The development of the construction industry entails the expansion of the range of products of building wall ceramics and an increase in the volume of their production. One of the promising areas of development can be considered the production of highly efficient ceramic stones from 2.1 $\mathrm{NF}$ and above. Currently, in the mining regions of the Rostov Region (East Donbass), the processing of heaps is actively carried out, primarily with the aim of extracting coal, which has become economically feasible and relevant. In the process of extracting coal from the heaps, a number of materials are formed, which vary in grain and chemical-mineralogical composition. In addition to coal, the content of which usually varies from 10 to $20 \%$, the main rocks that make up the waste heaps are siltstones, mudstones and sandstones [1-4].

The technology for the production of ceramic stones based on technogenic raw materials of the coal series has its own properties, which are associated with some features of the raw material. Replacing raw clay materials is possible in order to get a ceramic stone

* Corresponding author: Khungianos@mail.ru 
(block) with desired properties. A ceramic block in accordance with GOST 530-2012 was used as the basic product.

The greatest interest as a basic raw material for ceramics present screenings from the processing of heaps - these are medium-grained materials with a particle size of 2 to $6 \mathrm{~mm}$. They are not in demand for any other purposes, they are uniform in composition and, one might say, half-prepared for production. The main screening minerals are feldspars, quartz, mica, and hydromica. Feldspars are represented mainly by orthoclase and albite. They are subject to strong secondary changes - pellitization and chlorination. Hydromica (illite) is a typical clay mineral having the same type 2: 1 structural packet as montmorillonite, but unlike it, the tetrahedral layer always contains aluminum ions that isomorphically replace silicon ions, and the resulting charge of the packet is compensated by potassium ions. Secondary glandular minerals in the form of oxides and hydroxides are also present. For the production of ceramic samples, technogenic raw coal materials (screenings) are used with the addition of clay in the amount of $10-30 \%$. The ratios of these components may vary depending on the composition of the initial mountain dump [5-8].

\section{Characteristics of the initial materials, research methods and planning of the experiment, discussion.}

The following materials were taken as initial components:

- technogenic raw coal materials - screenings of processing of heaps;

- loam of the Chaltyr deposit as an additive.

The optimization of the composition of the ceramic mass using unconventional stonelike raw materials was carried out using mathematical planning methods. The experiment was carried out using the full factor experiment FFE $2^{3}$. The variable factors are following: $\mathrm{X}_{1}$ - firing temperature, ${ }^{\circ} \mathrm{C} ; \mathrm{X}_{2}$ - particle size distribution, fr., $\mathrm{X}_{3}$ - clay addition, $\%$. Factors used in the experiment and their variation levels are presented in Table 1.

Table 1. Factors and levels of variables.

\begin{tabular}{|l|c|c|c|c|}
\hline \multirow{2}{*}{ Name of indicator } & \multirow{2}{*}{ Symbols } & \multicolumn{3}{|c|}{ Factors } \\
\cline { 3 - 5 } & & $\mathrm{X}_{1}$ & $\mathrm{X}_{2}$ & $\mathrm{X}_{3}$ \\
\hline Minimum value & $\mathrm{X}_{\min .}$ & 900 & 0,16 & $10 \%$ \\
\hline Maximum value & $\mathrm{X}_{\max .}$ & 1100 & 0,63 & $30 \%$ \\
\hline Range of variation & $\Delta \mathrm{X}$ & 100 & 0,235 & $10 \%$ \\
\hline Main level & $\mathrm{X}_{0}$ & 1000 & 0,315 & $20 \%$ \\
\hline
\end{tabular}

The matrix of the plan FFE $2^{3}$ is presented in Table 2.

Table 2. The matrix of the plan FFE 23.

\begin{tabular}{|c|c|c|c|}
\hline \multirow{2}{*}{ № } & \multicolumn{3}{|c|}{ Pattern of coded factor values } \\
\cline { 2 - 4 } & $\mathrm{X}_{1}$ & $\mathrm{X}_{2}$ & $\mathrm{X}_{3}$ \\
\hline 1 & 1 & 1 & 1 \\
\hline 2 & 1 & 1 & -1 \\
\hline 3 & 1 & -1 & -1 \\
\hline 4 & 1 & -1 & 1 \\
\hline 5 & -1 & 1 & -1 \\
\hline 6 & -1 & 1 & 1 \\
\hline 7 & -1 & -1 & -1 \\
\hline 8 & -1 & -1 & \\
\hline
\end{tabular}


The responses are following:

- $\quad \mathrm{Y}_{1}$ - ultimate compressive strength, $\mathrm{R}_{\text {com, }} \mathrm{MPa}$;

- $\quad \mathrm{Y}_{2}$ - ultimate bending strength, $\mathrm{R}_{\text {bend, }} \mathrm{MPa}$;

- $\quad \mathrm{Y}_{3}$ - water absorption, $\mathrm{W}, \%$.

The preparation of the raw materials for the experiment was as follows: the screenings were dried in an oven at $\mathrm{t}=105^{\circ} \mathrm{C} \pm 5^{\circ} \mathrm{C}$, then they were crushed in a jaw crusher to the required fraction. Then clay was added in an amount of $10 \%, 20 \%$ and $30 \%$. The spray gun was used to moisten the mixture. Then the mixture was thoroughly mixed until normal molding moisture was obtained. After obtaining the desired consistency, the mass was thoroughly pressed and allowed to infuse for a day for an even distribution of moisture. Next, the molding samples of cubes 50 × 50 × $50 \mathrm{~mm}$ and sample-beam size $135 \times 30 \times 15$ $\mathrm{mm}$ were made. The samples were kept under normal conditions during the day and dried in an oven for 24 hours at $\mathrm{t} 105^{\circ} \mathrm{C}$. Further, the samples were fired at a given temperature. After firing, the samples were tested.

The results of the experiments and the values of the responses are presented in Table 3.

Table 3. The values of the responses.

\begin{tabular}{|c|c|c|c|}
\hline № & Rbend, & Rcom, & W, \\
\hline 1 & 6.08 & 17.3 & 16.76 \\
\hline 2 & 10.76 & 19.8 & 14.89 \\
\hline 3 & 20.17 & 56.9 & 4.41 \\
\hline 4 & 10.27 & 22.90 & 16.30 \\
\hline 5 & 10.42 & 47.00 & 14.14 \\
\hline 6 & 24.54 & 123.00 & 0.95 \\
\hline 7 & 9.24 & 28.30 & 18.66 \\
\hline 8 & 14.80 & 67.40 & 14.87 \\
\hline 9 & 27.48 & 61.80 & 0.34 \\
\hline
\end{tabular}

Mathematical processing of the obtained optimization results was created in such programs as Exel and MathCad. As a mathematical model, the semi-quadratic polynomial equation is chosen:

$$
Y=B_{0}+B_{1} X_{1}+B_{2} X_{2}+B_{3} X_{3}+B_{12} X_{1} X_{2}+B_{13} X_{1} X_{3}+B_{23} X_{2} X_{3}
$$

A statistical analysis of the obtained regression equations for each of the responses was evaluated according to three criteria: homogeneity of variances, significance of the coefficients, and adequacy, which was checked using the Fisher criterion [9-10]. As a result of the experiment and regression analysis of obtaining the values of the coefficients are presented in Table 4. 
Table 4. Regression Equation Coefficients.

\begin{tabular}{|c|c|c|c|c|c|c|c|}
\hline \multirow{2}{*}{$\begin{array}{c}\text { Name of } \\
\text { responses }\end{array}$} & \multicolumn{7}{|c|}{ The value of the coefficients } \\
\cline { 2 - 8 } & $\mathrm{B}_{0}$ & $\mathrm{~B}_{1}$ & $\mathrm{~B}_{2}$ & $\mathrm{~B}_{3}$ & $\mathrm{~B}_{12}$ & $\mathrm{~B}_{13}$ & $\mathrm{~B}_{23}$ \\
\hline $\mathrm{Y}_{1}$ & 48.83 & 14.08 & 27.63 & - & 8.48 & -8.13 & - \\
\hline $\mathrm{Y}_{2}$ & 14.61 & - & 8.33 & -1.70 & -1.12 & - & - \\
\hline $\mathrm{Y}_{3}$ & 10.14 & -0.22 & -7.36 & 0.78 & 0.6 & - & 1.34 \\
\hline
\end{tabular}

As a result of the implementation of the experimental design, the compositions of the ceramic masses of the product based on which are distinguished by a wide range of physical and mechanical properties are obtained. The range of variation of the experimental values of the studied parameters is given in Table 5 .

Table 5. Range of changes in key quality indicators.

\begin{tabular}{|c|c|c|}
\hline $\begin{array}{c}\text { Ultimate bending } \\
\text { strength, MPa; }\end{array}$ & $\begin{array}{c}\text { Ultimate } \\
\text { compressive } \\
\text { strength, MPa }\end{array}$ & Water absorption, \% \\
\hline $6.08-27.48$ & $17.3-123.0$ & $0.34-18.66$ \\
\hline
\end{tabular}

In practice, for the purpose of operational control of technological processes, various graphical constructions are usually used, which allow for any given $\mathrm{Y}=$ const to quickly establish values of varied factors taking into account the specifics of production. Moreover, $\mathrm{Y}=$ const corresponds to an infinite number of oscillations $\mathrm{X}_{\mathrm{i}}$, and the factors are already becoming independent and any of them becomes a function of the others. The most convenient form of graphical expression of the obtained dependences is the image on the plane, where one of the factors stabilizes at a constant level and the other two change in the given intervals of variation (Fig. 1-3). The use of such graphs helps to easily determine the conditions necessary to obtain products of one quality or another by strength, density, etc. With the help of such regression equations, it seems possible to determine the entire range of values of the output parameters in the studied area of the factor space, followed by a graphic representation of the nature of the change in the studied properties [11-12].

A general analysis of the effect of firing temperature, the fractional composition of screenings and clay additions on the compressive and bending tensile strength, and water absorption of calcined laboratory samples suggests that the obtained dependences are linear (Fig. 1-3). 


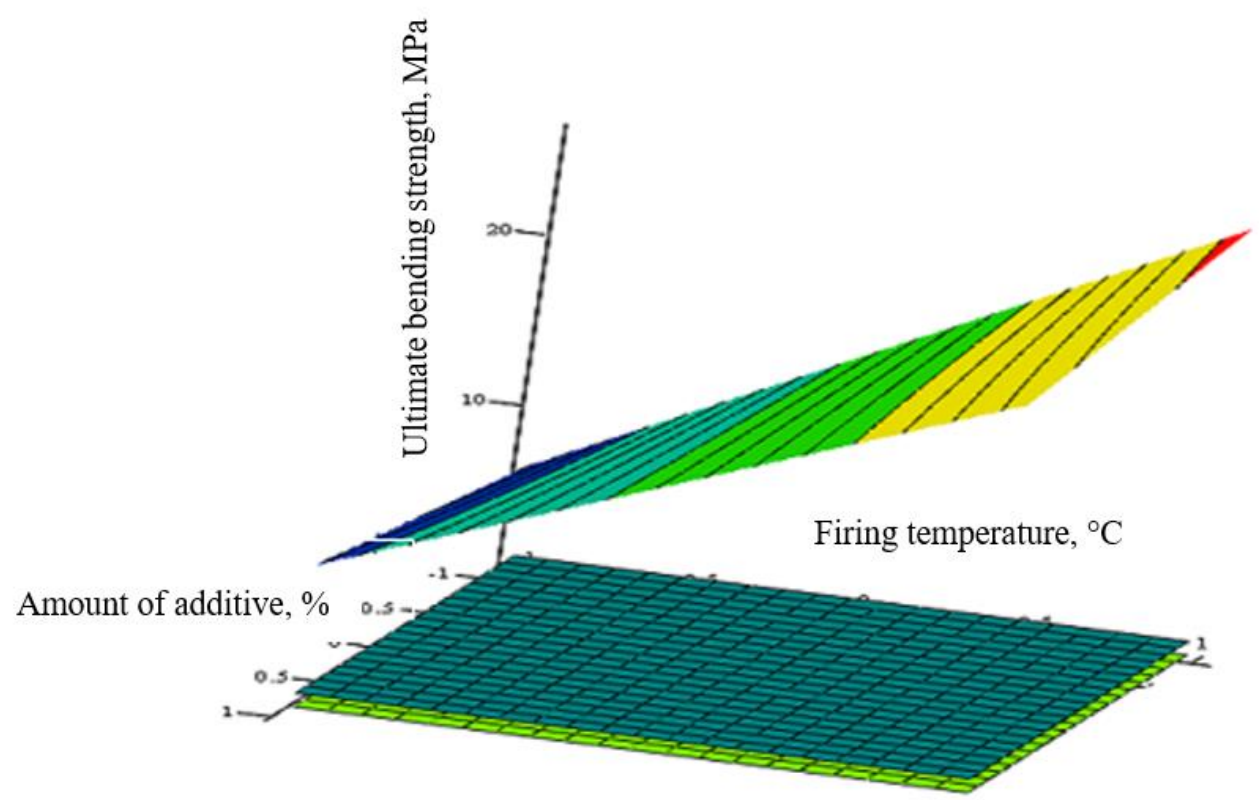

- average bending strength (1.6 MPa) for a ceramic block M125 according to the GOST 530-2012;

$\square$ - the smallest per sample $(0.8 \mathrm{MPa})$ for a ceramic block M125 according to the requirements GOST 530-2012

Fig. 1. The dependence of the bending strength on the firing temperature and clay consumption at a constant composition of $0.16 \mathrm{~mm}$.

Bending strength is one of the most important characteristics by which the brand of products is established and their quality is determined. Interpretation of the obtained dependence of the strength on the firing temperature and clay consumption with a constant grain composition showed that this indicator is most affected by the fractional composition of technogenic raw materials (screenings), and with a decrease in the grain composition from 0.63 to $0.16 \mathrm{~mm}$, the strength of the calcined samples significantly increases. This is explained by an increase in the contact area between grains and an increase in the degree of sintering.

According to experiments, an increase in the ultimate bending strength is caused by a decrease in clay consumption from 30 to $10 \%$, which is not entirely characteristic of ceramic technology. This is explained by the fact that screenings represented by siltstones are composed of fusible minerals: mica, hydromica, feldspars, ferruginous hydro aluminosilicates and other minerals. This contributes to active sintering with a certain degree of grinding and an optimal amount of finely divided fraction represented by clay minerals.

Changing the firing temperature also affects the ultimate bending strength. From the presented data (table 3), it is clearly seen that with increasing firing temperature the ultimate bending strength also increases, which is natural for ceramic technology. The greatest effect on strength is observed with increasing firing temperature and an increase in the degree of grinding screenings [13-15].

Compositions selected as a result of the experiment using heaps of processing of terriconics show that the calcined samples that were tested foe bending strength exceed the 
required average strength $(1.6 \mathrm{MPa})$ for the ceramic block of grade M125 according to GOST 530-2012 about 10 times. Given the high voidness of the blocks, it can reach the excess of strength up to 5 times. Thus, it can be concluded that ceramic products based on screenings of terriconics have a sufficiently high ultimate bending strength. The same dependences are also observed for the ultimate compressive strength. The influence of the studied factors on compressive strength can be ranked as follows: fractional screening composition $\mathrm{X}_{2}>$ firing temperature $\mathrm{X}_{1}>$ clay content $\mathrm{X}_{3}$. Moreover, as in the case with $\mathrm{R}_{\text {bend, }}$, with a decrease in the size of the fraction, the strength increases and $\mathrm{R}_{\text {comp }}$ increases with increasing temperature from 900 to $1100{ }^{\circ} \mathrm{C}$. This is also associated with an increase in the contact area between grains and an increase in the degree of sintering.

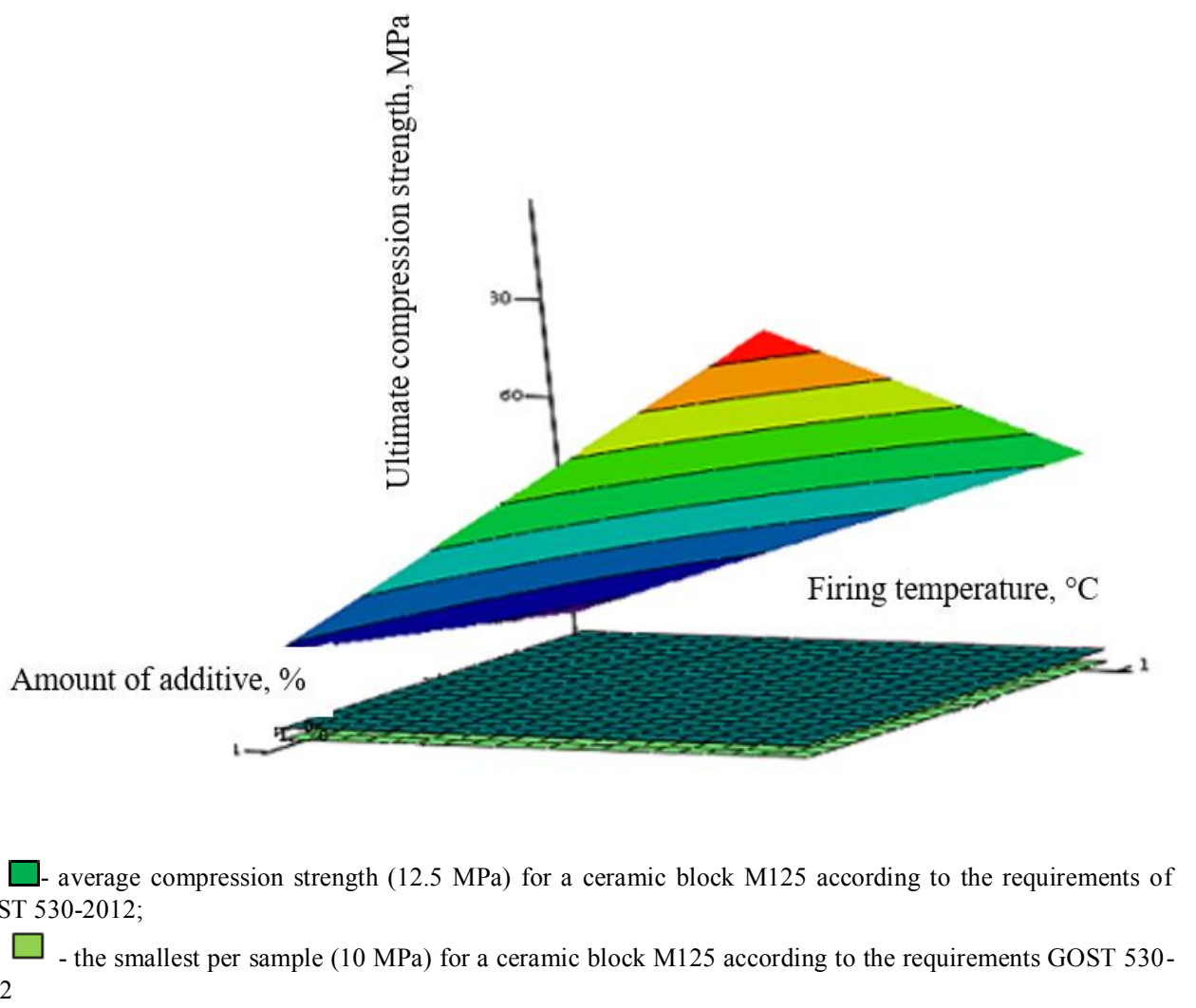

Fig. 2. The dependence of the compression strength on the firing temperature and clay consumption with a constant grain size equal to $0.16 \mathrm{~mm}$.

The compositions selected in the experiment using screenings of terriconics show that ceramic samples sufficiently high strength characteristics and fully comply with the requirements of GOST 530-2012. 


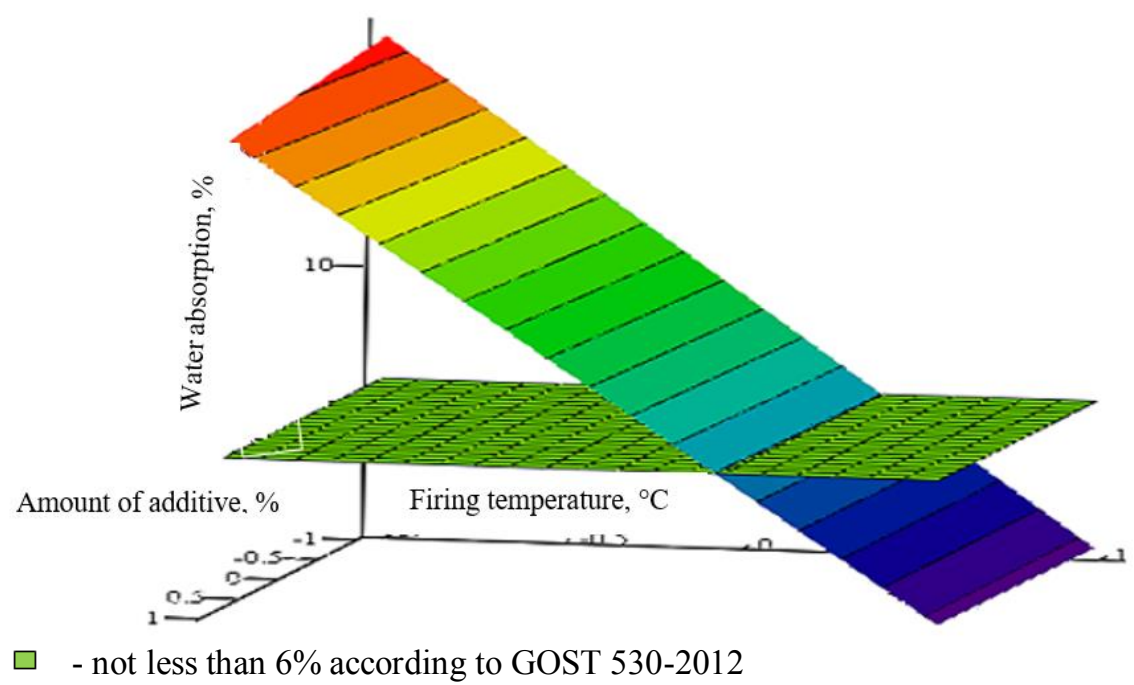

Fig. 3. The dependence of water absorption on the firing temperature and clay consumption with a grain composition of less than $0.16 \mathrm{~mm}$.

The analysis of the effect of the studied factors on water absorption shows that the fractional composition of the $\mathrm{X}_{2}$ screenings has the main influence on the studied indicator. At the same time, variable factors, the addition of clay $\left(\mathrm{X}_{3}\right)$ and the firing temperature $\left(\mathrm{X}_{1}\right)$, have almost no effect on the indicator. Thus, the ceramic crock after firing has the necessary porous structure, which in turn affects the water absorption of the material. The results obtained on the selection of the composition of ceramic masses using technogenic raw materials - screenings of processing of heaps show that the water absorption of the calcined samples directly depends on the firing temperature. The calcined samples show water absorption of more than $6 \%$ until the temperature reaches $1000{ }^{\circ} \mathrm{C}$, and less than $6 \%$ with the increase in temperature up to $1100{ }^{\circ} \mathrm{C}$. All this makes elimination screenings of terriconics a very promising raw material for high-performance ceramic blocks, which are the most promising wall products for modern construction.

\section{References}

1. K.S. Yavruyan, V.D.Kotlyar, Gayshun E.S. Resource-efficient technologies in the construction complex of the region 2, 162-167 (2018).

2. F. Pacheco-Torgal, P.B. Lourenço, J.A. Labrincha, S. Kumar, P. Chindaprasirt, Ecoefficcient Masonry Bricks and blocks, Desing, Properties and Durability (Elsevier Ltd., 2015).

3. V.D. Kotlyar, H.S. Yavruyan, Building material 4, 38-41 (2017).

4. A.I. Seregin, Processing of coal sludge into marketable products by nontraditional physicochemical effects: diss. Cand. tech. sciences (2009).

5. A.Z. Zolotarsky, E.Sh Sheiman, Production of ceramic bricks (1989).

6. A.Yu. Stolboushkin, A.I. Ivanov, O.A. Fomina, International Conference on Industrial Engineering, ICIE 2016, Procedia Engineering 150, 1496-1502 (2016). 
7. V.D. Kotlyar, A.V. Ustinov, Yu.V. Terekhina, A.V. Kotlyar, Technique and technology of silicates 4, 8-15 (2014).

8. P. MuñozVelasco, M.P. MoralesOrtíz, M.A. MedívilGiró, L. MuñozVelasco, Construction and Building materials 63, 97-107 (2014).

9. V. Kotlyar, K. Yavruyan, E. Gaishun,Y. Teryokhina, IEEE International Conference "Management of Municipal Waste as an Important Factor of Sustainable Urban Development" (WASTE), 22-24 (2018); doi:10.1109/waste.2018.8554158

10. I.A. Serebryanaya, A.A. Matrosov, N.A. Poryadina, A.N. Soloviev Materials and Technologies in Construction andArchitecture II. 2nd International Scientific Conference "Constructionand Architecture: Theory and Practice for the innovation Development"(CATPID-2019) 974, 510-514 (2020) https://www.scientific.net/MSF.974.510.

11. O.A. Fomina, A.Yu. Stolboushkin, Materials Today: Proceedings (2019).

12. A.Y. Stolboushkin, A.I. Ivanov, O.A. Fomina, Solid State Phenomena (2018).

13. G.I. Storozhenko, A.U. Stolboushkin, Ceramik \& Sakhteman. Seasonal magazine of Ceramic \& Building 2,. 2-6 (2010).

14. Yu.V. Terekhina, K.A. Lapunova, A.V. Kotlyar, M.E. Orlova, Ya.V. Lazareva, R.A. Yaschenko, Yu.A. Bozhko, Atlantis Highlights in Material Sciences and Technology (AHMST) 1, 328-332 (2019).

15. A.Yu. Stolboushkin, D.V. Akst, O.A. Fomina, A.I. Ivanov, V.A. Syromyasov, IOP Conference Series: Earth and Environmental Science (2017). 